\title{
Performance and competitiveness of red vs. green phenotypes of a cyanobacterium grown under artificial lake browning
}

\author{
Kevin Erratt ${ }^{\mathrm{a}}$, Irena Creed ${ }^{\mathrm{b}, *}$, Camille Chemali, Alexandra Ferrara, Vera Tai and Charles \\ Trick $^{\mathrm{a}}$
}

Department of Biology, Western University, 1151 Richmond Street N, London, ON N6A 5B7, Canada

Increasing inputs of dissolved organic matter (DOM) to northern lakes is resulting in 'lake browning.' Lake browning profoundly affects phytoplankton community composition by modifying two important environmental drivers-light and nutrients. The impact of increased DOM on native isolates of red and green-pigmented cyanobacteria identified as Pseudanabaena, which emerged from a Dolichospermum bloom (Dickson Lake, Algonquin Provincial Park, Ontario, Canada) in 2015, were examined under controlled laboratory conditions. The genomes were sequenced to identify phylogenetic relatedness and physiological similarities, and the physical and chemical effects of increased DOM on cellular performance and competitiveness were assessed. Our study findings were that the isolated red and green phenotypes are two distinct species belonging to the genus Pseudanabaena; that both isolates remained physiologically unaffected when grown independently under defined DOM regimes; and that neither red nor green phenotype achieved a competitive advantage when grown together under defined DOM regimes. While photosynthetic pigment diversity among phytoplankton offers niche-differentiation opportunities, the results of this study illustrate the coexistence of two distinct photosynthetic pigment phenotypes under increasing DOM conditions.

Key Words: cyanobacteria; dissolved organic matter; genome; lake browning; pigments; Pseudanabaena

Abbreviations: BBM, Bold Basal's Medium; DOM, dissolved organic matter; KEGG, Kyoto Encyclopedia of Genes and Genomes; PC, phycocyanin; PE, phycoerythrin; P-E curve, photosynthesis-energy curve

\section{INTRODUCTION}

Lake browning has a profound effect on a lake's physicochemical properties, and these modifications have been suggested as factors stimulating cyanobacteria growth and dominance (Ekvall et al. 2013, Urrutia-Cordero et al. 2016). Dissolved organic matter (DOM) acts as a nutrient vector, increasing nutrient concentrations in receiving surface waters but not necessarily nutrient availability. DOM modifies the underwater light climate reducing the light quantity and changing spectral quality (Stomp et al. 2007, Karlsson et al. 2009, Kritzberg et al. 2019). While light quantity is crucial for driving phytoplankton productivity, spectral quality changes can play a fundamental role in niche-differentiation among and within major phytoplankton groups (Huisman et al. 1999, Stomp et al. 2004, 2007). The rich diversity of accessory pigments observed among phytoplankton allows species to exploit different parts of the visible light spectrum, thus providing opportunities for niche-differentiation with lake browning (Stomp et al. 2007, Grébert et al. 2018).
(P) $\$$ This is an Open Access article distributed under the terms of the Creative Commons Attribution Non-Commercial License (http://creativecommons.org/licenses/by-nc/3.0/) which permits unrestricted non-commercial use, distribution, and reproduction in any medium, provided the original work is properly cited.
Received March 4, 2021, Accepted July 19, 2021

* Corresponding Author

E-mail: irena.creed@utoronto.ca

Tel: +1-416-208-4835

${ }^{\mathrm{a}}$ Present address: Department of Biology, University of Saskatchewan, 112 Science Place, Saskatoon, SK S7N 5E2, Canada

${ }^{\mathrm{b}}$ Present address: Office of the Vice Principal Research \& Inno-

195 vation, University of Toronto Scarborough, 1265 Military Trail, Toronto, ON M1C 1A4, Canada 
Competition for light and nutrients exerts intense selective pressure on phytoplankton communities. The light attenuating properties and nutrient subsidies associated with DOM both affect phytoplankton growth dynamics, complicating the experimental challenge when examining individual effects which may be combinatorial in nature (Wells et al. 2015, Creed et al. 2018). One alternative to these experimental challenges is the use of "lakes of opportunity." Dickson Lake in Algonquin Park, Ontario, Canada represents one of these "lakes of opportunity." The 2015 cyanobacteria bloom in Dickson Lake was dominated by Dolichospernum sp. (Favot et al. 2019). While the exact drivers of the Dolichospermum bloom in Dickson Lake are not well understood, it has been postulated that the onset of the bloom in the fall of 2014 may have coincided with the rupture of a beaver dam embedded in the catchment (Friends of Algonquin Park 2015). The warm, DOM-rich waters entering the lake from the breached dam could have created a DOM- and nutrientenriched, warm water epilimnion-parallel to how lake browning alters oligotrophic freshwaters. For this period, Dickson Lake represented a scenario purported to occur in many northern, temperate lakes based on our present understanding of climate change (Solomon et al. 2015, Creed et al. 2018).

Co-occurring within the Dolichospermum bloom were two Pseudanabaena-like organisms at background levels, each with different pigmentation resulting in green and red phenotypes. Unialgal blooms are generally rare, as blooms are often composed of a complex array of species that coexist through changes in physiological attributes or preferences, and micro-physical and micro-nutrient differences in a spatial-temporal matrix (Hutchinson 1961). Pseudanabaena is a non-heterocystous, filamentous genus inhabiting waterbodies across the globe. Although rarely observed as a dominant bloom-forming genus, Pseudanabaena species are known for co-occurring within other cyanobacteria blooms at lower densities and have the capacity to synthesize cyanotoxins and taste and odour compounds (e.g., geosmins). Some Pseudanabaena species display complementary chromatic adaptation-regulating the ratio of phycoerythrin (PE) and phycocyanin (PC) phytosynthetic pigments (Kling et al. 2012). In nature, PE- and PC-rich Pseudanabaena can coexist as each organism is specialized for utilizing different wavelengths within the visible light spectrum-a form of resource partitioning (Stomp et al. 2007).

Theoretically, each phenotype should exist under different light regimes (i.e., the green phenotype in turbid conditions, and the red phenotype under clear condi- tions). However, if a particular species exhibits chromatic adaptation-altering pigment composition in response to changing light conditions-then the cyanobacterium can exist under both water transparency extremes (Stomp et al. 2004, Kehoe 2010). In less turbid waters, shorter wavelengths of the visible light (green and yellow) penetrate deeper into the water column resulting in a greater abundance of PE-rich organisms, as PE absorbs photons in the green part of the spectrum (Stomp et al. 2004, Haverkamp et al. 2009). In contrast, under turbid conditions (i.e., lake browning), the rapid attenuation of shorter wavelengths results in the prevalence of longer wavelengths (i.e., orange and red) (Stomp et al. 2007, Pagano et al. 2014) and a greater abundance of PCrich organisms, as $\mathrm{PC}$ absorbs photons in the red part of the spectrum (Stomp et al. 2004, Oberhaus et al. 2007, Haverkamp et al. 2009). The coexistence of two phenotypically distinct Pseudanabaena in Dickson Lake may represent an example of a phytoplankton competition outcome based on altered light regimes created through DOM additions.

In this laboratory-based study, we examined the effect of DOM on the physiology and competitiveness of the red and green phenotypes. We performed a detailed genetic and morphological analysis before the physiological experiments to gain insight into each isolate. We hypothesized that chromatic adaptation allowed for the coexistence of two Pseudanabaena phenotypes in Dickson Lake. DOM-driven changes in color or nutrients would enhance the cellular growth and photosynthetic parameters of PC-rich green phenotype relative to PErich red phenotype.

\section{MATERIALS AND METHODS}

\section{Phenotypic and genetic characterization of Pseudanabaena-like organisms}

Two phenotypically distinct Pseudanabaena-like organisms - green (UWO310) and red (UWO311) colored phenotypes (Fig. 1)-were isolated from a Dolichospermum sp. bloom occurring in Dickson Lake $\left(45^{\circ} 47^{\prime} \mathrm{N}\right.$, $78^{\circ} 12^{\prime} \mathrm{W}$ ), located in a remote wilderness at the heart of Algonquin Park, Ontario, Canada in 2015. Both Pseudanabaena-like organisms were maintained as non-axenic, unialgal strains on Bold Basal's Medium (BBM) (Andersen 2005) at $22 \pm 1^{\circ} \mathrm{C}$ under a continuous light flux of $45 \pm 5$ $\mu \mathrm{mol}$ photons $\mathrm{m}^{-2} \mathrm{~s}^{-1}$ (daylight fluorescent light). Isolates were grown on an orbital shaker at $100 \mathrm{rpm}$ to reduce ad- 

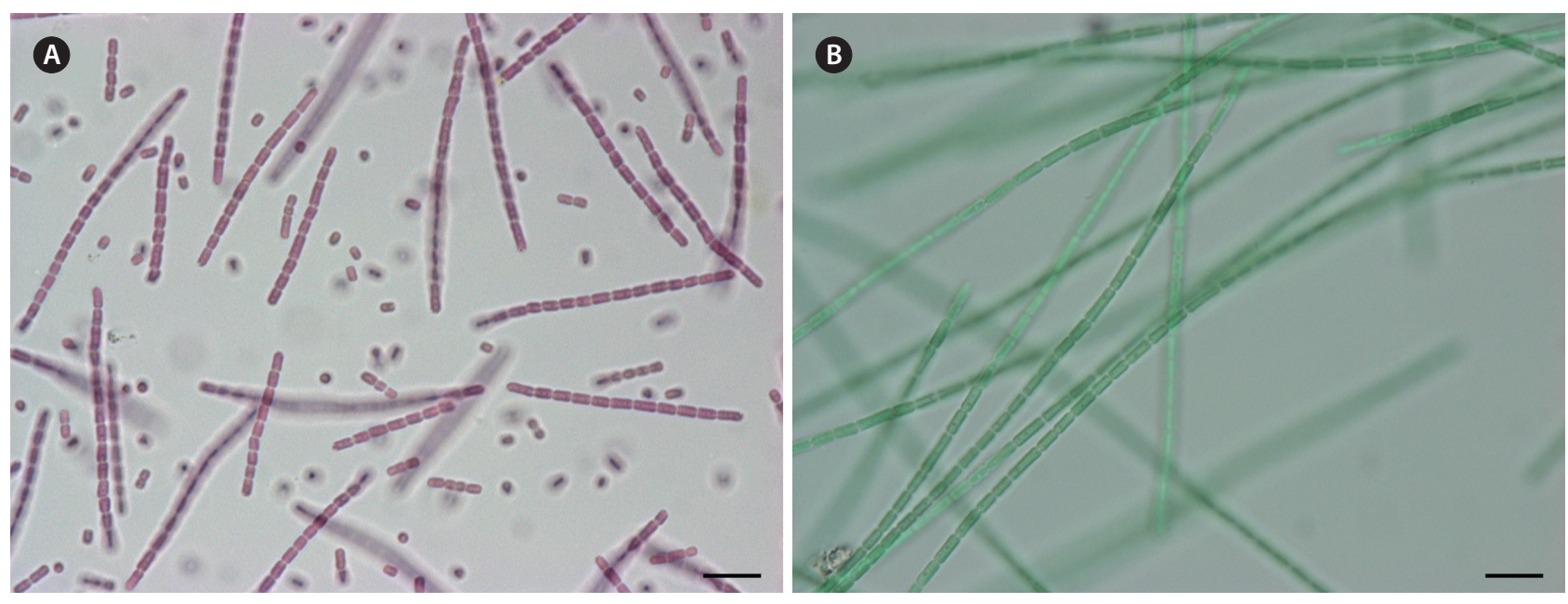

Fig. 1. Light micrographs of red and green Pseudanabaena phenotypes. (A) Red phenotype at $\times 40$. (B) Green phenotype at $\times 40$. Scale bars represent: $A \& B, 10 \mu \mathrm{m}$.

hesion and to aid in cell development.

Morphological and pigment analysis. The Pseudanabaena-like isolates were cultured in BBM (as above) and harvested during the exponential growth phase to ensure cell physiology represented nutrient replete conditions. Absorption spectra were determined by scanning whole cells between $400-800 \mathrm{~nm}$ wavelengths on a UV-Visible Spectrophotometer (Agilent Technologies, Santa Clara, CA, USA). Absorption peaks of major phycobilins, PE $(565 \mathrm{~nm})$ and PC $(620 \mathrm{~nm})$, were then visibly discerned from absorption spectra to detect the presence or absence of phycobilins. Micrographs of the Pseudanabae$n a$-like isolates were taken under $400 \times$ (red phenotype) and 200× (green phenotype) magnification with a compound microscope. Cell length and width, along with trichome length, were taken from 250 randomly selected trichomes.

Genome sequencing. Cultured isolates of UWO310 and UWO311 were collected by centrifugation at 10,000 $\times \mathrm{g}$ for $5 \mathrm{~min}$ at $4^{\circ} \mathrm{C}$, and the pelleted cells were stored at $-20^{\circ} \mathrm{C}$. Genomic DNA was extracted using a GeneJET DNA Genomic DNA Purification kit (ThermoFisher Scientific, Waltham, MA, USA) following the manufacturer's protocol. Sequencing libraries were prepared from the genomic DNA using a Nextera XT kit (Illumina, San Diego, CA, USA), and $2 \times 250$ bp sequence reads were obtained using a MiSeq instrument (Illumina). Low-quality bases (quality score $<20$ ) and adapter sequences were trimmed from these sequences using Cutadapt v 1.14 (Martin 2011), and sequences longer than $50 \mathrm{bp}$ in length were retained. The trimmed sequences were assembled into contigs using SPAdes version 3.5.0 (Bankevich et al.
2012). As the cultures were not axenic, contigs originating from contaminating bacteria were identified using BLASTN searches against GenBank's nt database. Only contigs best hits to cyanobacterial sequences with evalues less than $10^{-10}$ were retained as belonging to the UWO310 or UWO311 genomes.

Summary statistics were calculated for the collection of contigs comprising the UWO310 and UWO311 genomes using QUAST v4.5 (Gurevich et al. 2013), and genome completeness for each strain was tested using BUSCO v3 (Simão et al. 2015). Open reading frames were annotated from the contigs using Prokka v1.12 (Seemann 2014). The genome sequences of strains UWO310 and UWO311 have been deposited in GenBank under accession numbers SELU00000000 and SJEE00000000, respectively. The versions described in this paper are versions SELU01000000 and SJEE01000000.

165 ribosomal RNA gene phylogeny. MAFFT v7.271 (Katoh and Standley 2013) was used to align 16S ribosomal RNA (rRNA) gene sequences from the UWO310 and UWO311 genomes with 16S rRNA sequences from diverse Pseudanabaena and related Synechococcales strains available from GenBank. We included sequences from two strains (SAG 254 and PCC 7408) named as Pseudanabaena catenata, which is the type species for Pseudanabaena; however, neither of these strains are derived from the original type specimen. As a result, the molecular phylogeny of the original type specimen for Pseudanabaena is not known. This is problematic taxonomically because strains classified as Pseudanabaena and other related genera are polyphyletic, and the original Pseudanabaena type specimen may not be closely related to 
SAG 254 and PCC 7408. Nevertheless, these strains are known to belong to a clade conventionally considered as Pseudanabaena and we used these strains to represent the genus (Rippka et al. 1979, Konstantinou et al. 2021). The alignment was trimmed, and alignment gaps were removed using trimAl v1.2 and the gappyout option (Capella-Gutiérrez et al. 2009). A maximum-likelihood phylogenetic tree was constructed with a GTR + gamma model of nucleotide substitution using RAxML v8 (Stamatakis 2014). Statistical support for the branches of the most likely tree was calculated from 1,000 bootstrap replicates. A phylogeny was also inferred from a Bayesian analysis using MrBayes (v3.2.7a) and a GTR + gamma model (Ronquist et al. 2012). Four chains were sampled every 500 generations from 2 runs for 1,000,000 generations. Diagnostics were run every 5,000 generations after a relative burn-in of $25 \%$ of the sampled trees. After $1,000,000$ generations, the average standard deviation of the split frequencies from the 2 runs was 0.005 .

Analysis of pigment synthesis genes. The presence or absence of phycobilisome synthesis genes in the UWO310 or UWO311 genomes was determined using Kyoto Encyclopedia of Genes and Genomes (KEGG)'s BlastKOALA annotation tool, which uses BLASTP searches against KEGG's prokaryote database to identify homologs, and KEGG's reconstruct pathway mapper tool (Kanehisa et al. 2016). The genome of Pseudanabaena biceps PCC 7429 (NZ_ALWB01000352), a closely related strain, was also analyzed as a comparison.

\section{Growth and physiology experiments}

Three experiments were performed to understand the physical and chemical effects of DOM on each organism's cellular performance: (1) a single isolate experiment, where each organism was cultured independently with increasing DOM additions directly to the BBM medium, altering the nutrient and light regime; (2) similar to experiment 1, except that isolates were exposed to DOM external to the growth media, altering the light regime only; and (3) a competition experiment in which both organisms were added to the same culture vessel and exposed to increasing DOM supplied to the growth media.

In all experiments, organisms were exposed to different browning scenarios, using a DOM proxy-Suwannee River natural organic matter (Green et al. 2015) - to mimic the effects of lake browning. Experimental treatments represented increasing the color of the water from clear to brown waters in northern Ontario systems $(0,100,200$, and 400 true color units) (Neary et al. 1990). DOM ad-
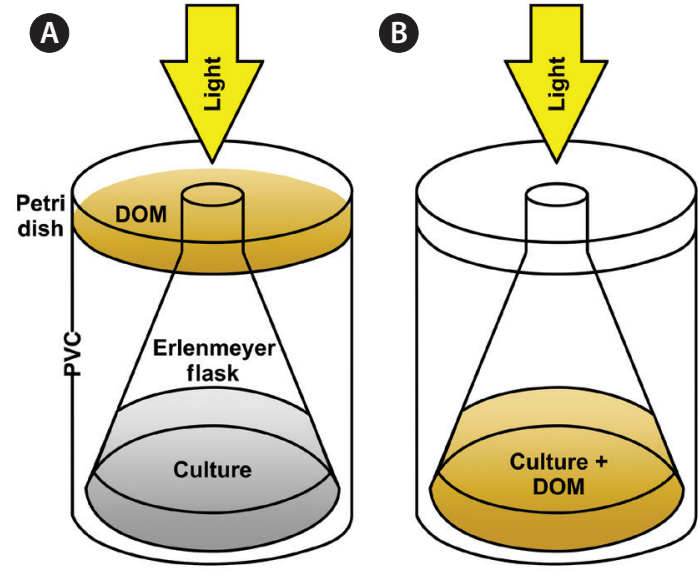

Fig. 2. Experimental setup used to investigate the physical effects of dissolved organic matter (DOM) (A) and the physical and chemical effects of the DOM (B).

ditions were measured at an absorbance of $420 \mathrm{~nm}$ and then transformed to true color units (TCU) with the use of a certified color reference (Pt/Co) (Senar et al. 2021). Experiments were carried out in $125 \mathrm{~mL}$ Erlenmeyer flasks and the experimental inoculum was established at a low concentration $\left(\mathrm{OD}_{750} \sim 0.08\right)$ to reduce the likelihood of self-shading.

The experimental apparatus to distinguish between externally supplied DOM (with only light modified) and internally supplied DOM (with light and DOM-associated nutrients modified) is presented in Fig. 2. In the second experiment, defined concentrations of dissolved organic carbon were created and placed in a petri dish located between the light source and the cultures. The culture flask itself was enclosed in an opaque cylinder (i.e., PVC tubing) to eliminate extraneous light that did not pass through the DOM-solution (Fig. 2A). In the first and third experiments, similar DOM concentrations were provided directly to the growth medium and the light was provided from above without attenuation (Fig. 2B).

\section{Performance measurements for single isolate experiments (expt. 1 and 2)}

For the first and second experiments, cell densities were logged daily, beginning from the initial inoculation (day 0) and continuing until cells reached the stationary growth phase. Cell density was determined through daily measurements using optical density (at $\mathrm{OD}_{750} \mathrm{~nm}$ ) on a UV-Visible Spectrophotometer. $\mathrm{OD}_{750} \mathrm{~nm}$ represents particle density and is less prone to pigment interference, due to the wavelength extending past the range of 
photosynthetic pigments. Optical density measurements were calibrated to hemocytometry counts, allowing the estimation of cell concentrations (cells $\mathrm{mL}^{-1}$ ).

Growth rate, cell yield, and physiological measurements (pigment concentrations and light-specific oxygen evolution) were calculated from data collected during the mid-exponential phase ( 4 to 7 days after innoculation). Growth rate $\left(\mu, \mathrm{d}^{-1}\right)$ was calculated using the equation: $\mu\left(\mathrm{d}^{-1}\right)=\ln \left(\mathrm{N}_{1} / \mathrm{N}_{0}\right) /\left(\mathrm{t}_{1}-\mathrm{t}_{0}\right)$, where $\mathrm{N}_{1}$ is the final cell density, $\mathrm{N}_{0}$ is the initial cell density, and $\mathrm{t}_{1}-\mathrm{t}_{0}$ is the time in that elapsed (days) (Guillard 1973, Wood et al. 2005). Cell yield (a proxy of the organism's maximal biomass under defined light, DOM, and nutrient conditions, $Y$, cells $\mathrm{mL}^{-1}$ ) was calculated by averaging the cell densities from three consecutive days once the culture reached stationary phase.

Pigment content was assessed using the methods outlined in Erratt et al. (2018). In short, cells were collected on a series of Whatman $25 \mathrm{~mm}$ GF/F filters (Pall Life Sciences, Mississauga, ON, Canada), macerated using a Bead-Beater (BioSpec Products, Inc., Bartlesville, OK, USA), and then extracted with $90 \%$ acetone for chlorophyll- $a$ (Chl- $a$ ) (Jeffrey and Humphrey 1975) or phosphate buffer for phycobilins (PE and PC) (Lawrenz et al. 2011). Phycobilin samples were then incubated at $4^{\circ} \mathrm{C}$ and Chl- $a$ samples at $-20^{\circ} \mathrm{C}$ for $24 \mathrm{~h}$ followed by centrifugation to remove particulates. Absorbance at 664 and $647 \mathrm{~nm}$ indicate the level of Chl- $a$ (Jeffrey and Humphrey 1975), and absorbance at 545 and $620 \mathrm{~nm}$ indicate the level of PE and PC, respectively (Lawrenz et al. 2011). An empirically-derived equation created by Jeffrey and Humphrey (1975) was used to quantify the Chl- $a$ content, whereas equations from Lawrenz et al. (2011) were used to quantify PE and PC content.

The photosynthetic capacity of cells was generated from photosynthesis-energy (P-E) curves. A Chlorolab 2 System (Hansatech, King's Lynn, Norfolk, UK) was used to measure photosynthesis through changes in photosynthetically produced dissolved $\mathrm{O}_{2}$ levels. To ensure $\mathrm{CO}_{2}$ was not limiting during the measurements, sodium bicarbonate $\left(\mathrm{NaHCO}_{3}\right)$ was introduced at a final concentration of $4 \mathrm{mM}$ to each sample. Samples were exposed to 12 pre-selected light intensities, and the rate of change in oxygen concentrations was used to generate P-E curves. Prior to light exposure, cells were incubated for $4 \mathrm{~min}$ in the darkness to calculate respiration rates. The difference between $\mathrm{O}_{2}$ evolved during photosynthesis and respiration at each photon flux allowed the determination of light-specific $\mathrm{O}_{2}$ evolution rates. Light absorption rate (the slope, $\alpha$ ) and the light saturation point $\left(\mathrm{P}_{\max }\right)$ were determined with the generated P-E curve (Maxwell et al. 1994).

\section{Performance measurements for the competition experiment (expt. 3)}

For the third experiment, BBM media were inoculated with both isolates (UWO310 and UWO311) at a low concentration $\left(\mathrm{OD}_{750} \sim 0.08\right)$. Changes in relative abundances of each organism were tracked over time. The relative abundance of each organism was assessed with an upright epifluorescence microscope, using distinct fluorescence signals to identify PE- and PC-rich taxa. When PErich cells are exposed to blue light, they emit an intense yellow to orange fluorescence, whereas when PE- and PC-rich cells are exposed to green light, both organisms emit an intense orange to red fluorescence. The superimposition of both images captured under green and blue light allowed for the differentiation of each organism (Stomp et al. 2007). To limit cell movement and increase image resolution, cells were fixed with glutaraldehyde prior to being loaded into a hemocytometer to simultaneously quantify cell abundance (Guillard and Sieracki 2005). Cell counts from nine hemocytometer grids were averaged. Cell volumes were calculated from the average cell dimensions.

\section{Statistical analyses}

Experiments were run in triplicates, with each experiment comprised of three replicates. A two-way analysis of variance (ANOVA) with post-hoc Tukey's analyses were performed to assess differences in responses between different phenotypes (i.e., red vs. green) and DOM conditions (i.e., TCUs) (experiments 1 and 2). One-way (ANOVA) post-hoc Tukey's analyses were used to determine whether responses between the red and green phenotypes were statistically significant in the competition experiment (experiment 3) and morphological comparison.

\section{RESULTS}

\section{Phenotypic characterization}

Trichome length for the green (UWO310) isolate (312.2 $\mu \mathrm{m}$ ) was about $10 \times$ greater than the red (UWO311) isolate $(33.3 \mu \mathrm{m})(\mathrm{p} \leq 0.05)$. Cell length for the green isolate (5.3 $\mu \mathrm{m})$ was about $2 \times$ greater than the red isolate $(2.5 \mu \mathrm{m})$. 

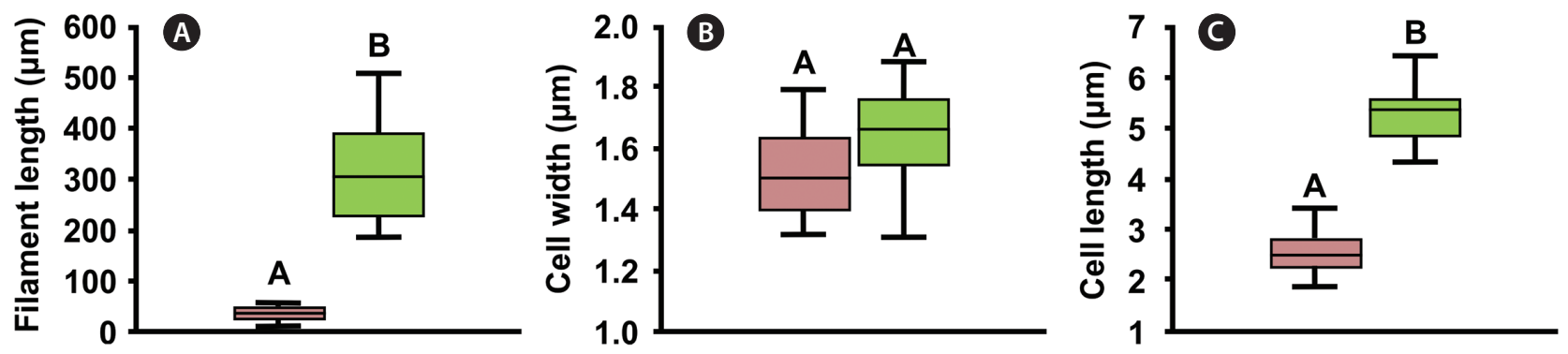

Fig. 3. Morphological attributes of red and green Pseudanabaena phenotypes. (A) Filament length ( $\mu \mathrm{m})$. (B) Cell width ( $\mu \mathrm{m})$. (C) Cell length ( $\mu \mathrm{m})$. Same uppercase letters indicate no significant effects among the phenotypes. Significance tested at $\mathrm{p} \leq 0.05$ level.

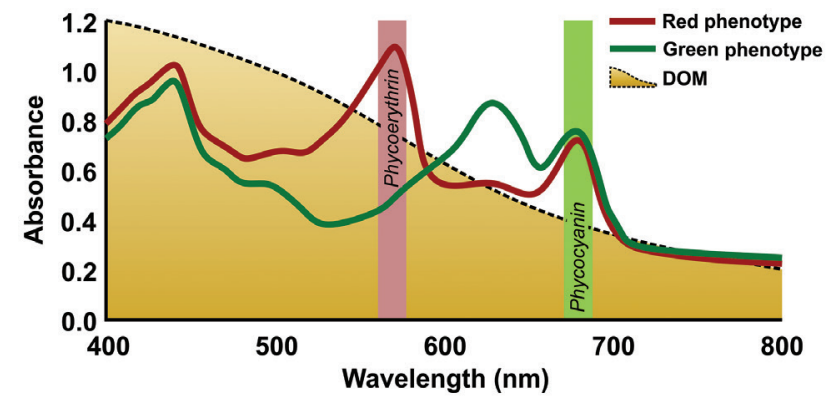

Fig. 4. Absorbance spectra of dissolved organic matter (DOM) and the red and green phenotypes of Pseudanabaena. Absorption maxima of phycoerythrin $(565 \mathrm{~nm})$ is indicated with a red highlight, whereas phycocyanin $(620 \mathrm{~nm})$ is indicated with a green highlight.

Cell width was not significantly different between the two phenotypes ( $\mathrm{p} \leq 0.05)$ (Fig. 3). The dominant accessory pigment found in the green isolate is $\mathrm{PC}$, while $\mathrm{PE}$ appeared absent. In contrast, the dominant accessory pigment found in the red isolate is $\mathrm{PE}$, although the isolate also contained PC (Fig. 4).

\section{Genetic characterization}

UWO310 and UWO311 were closely related but had distinct genomes and phylogenetic relationships. DNA sequencing resulted in 1,120,964 and 1,997,417 paired- end reads from non-axenic cultured strains of UWO310 and UWO311, respectively. After assembling contigs and removing non-cyanobacterial contigs, the contigs were estimated to represent 92.3 and $95.3 \%$ of the genomes of UWO310 and UWO311, respectively. The number of genes and GC content for both genomes are typical of previously sequenced Pseudanabaena genomes (Table 1), but their genomes are clearly distinct from one another. In comparing the two genomes, homologous genes between UWO310 and UWO311 shared on average $77.6 \%$ amino acid identity.

A phylogenetic tree of the 16S rRNA gene sequences strongly supported UWO310 and UWO311 as members of a clade of Pseudanabaena cyanobacteria, which includes strains identified as the type species P. catenata (Fig. 5). In similar but distinct clusters, UWO310 was most closely related to Arthronema gigaxiana and UWO311 was most closely related to Limnothrix redekei CCAP 1443/1, which is phylogenetically distant from L. redekei 165c (Fig. 5).

UWO310 and UWO311 had all core genes for the synthesis of PC. However, UWO310 did not have any genes associated with PE synthesis, except for CpeS (Fig. 6), explaining their lack of PE in pigment analysis and indicating their inability to adapt chromatically. In contrast, UWO311 had all of the core genes necessary, except CpeE, to synthesize PE (Fig. 6).

Table 1. Assembly and annotation statistics for Pseudanabaena strains UWO310 and UWO311, and for previously sequenced genomes of closely related Pseudanabaena strains

\begin{tabular}{|c|c|c|c|c|c|c|}
\hline Strain (GenBank ID) & $\begin{array}{c}\text { No. } \\
\text { of contigs }\end{array}$ & $\begin{array}{c}\text { No. } \\
\text { of genes }\end{array}$ & $\begin{array}{c}\text { Total length } \\
(\mathrm{Mb})\end{array}$ & $\begin{array}{c}\text { GC content } \\
(\%)\end{array}$ & $\mathrm{N}_{50}$ & $\begin{array}{c}\text { Genome } \\
\text { completeness }(\%)\end{array}$ \\
\hline UWO310 (SELU01000000) & 132 & 4,417 & 5.26 & 43.44 & 65,620 & 93.2 \\
\hline UWO311 (SJEE01000000) & 61 & 4,695 & 5.21 & 41.98 & 126,236 & 95.3 \\
\hline $\begin{array}{l}\text { Pseudanabaena biceps PCC } 7429 \\
\text { (NZ_ALWB01000352) }\end{array}$ & 464 & 4,803 & 5.48 & 43.20 & 20,529 & 95.0 \\
\hline $\begin{array}{l}\text { Pseudanabaena sp. PCC } 6802 \\
\text { (NZ_ALVK01000000) }\end{array}$ & 46 & 3,667 & 5.62 & 47.80 & 3.042 & N/A \\
\hline
\end{tabular}

$\mathrm{N} / \mathrm{A}$, not available. 


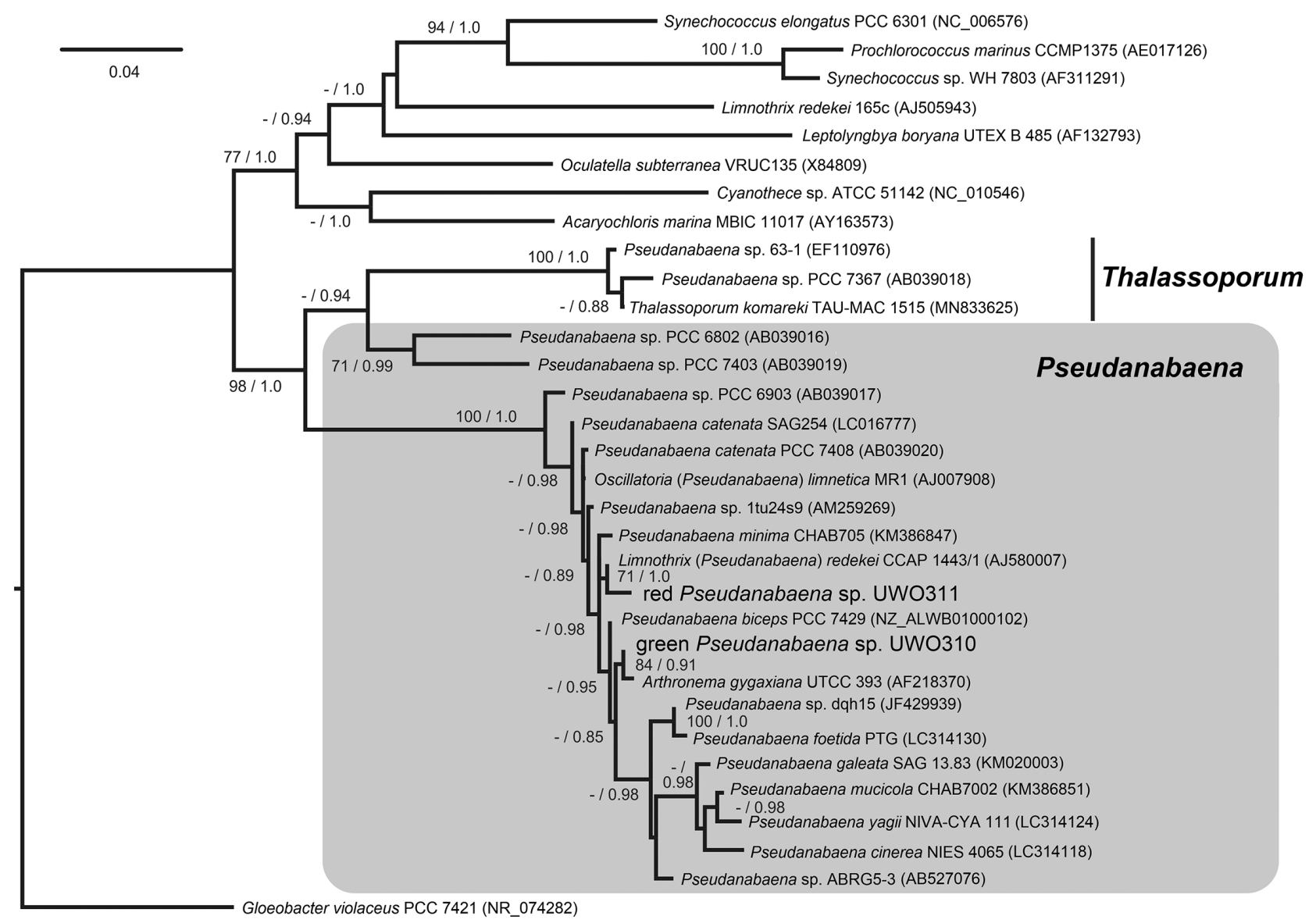

Fig. 5. Maximum likelihood phylogenetic tree from an alignment of $16 \mathrm{~S}$ rRNA gene sequences from the green and red isolates of Pseudanabaena from Dickson Lake (UWO310 and UWO311, respectively) and closely related cyanobacteria. Branch support is shown for bootstrap values when greater than $70 \%$ and Bayesian posterior probabilities when greater than 0.80 . Values below these thresholds are indicated by '-'. The grey box indicates strains conventionally considered as Pseudanabaena (or should be re-classified as Pseudanabaena).

\section{Allophycocyanin}

\begin{tabular}{|l|l|l|}
\hline ApcA ApcB ApcC ApcD ApcE ApcF & 0
\end{tabular}

\section{Phycocyanin / Phycoerythrocyanin}

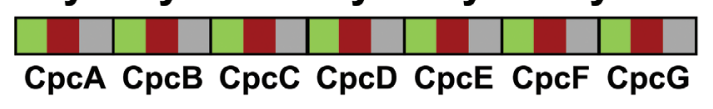

\section{Phycoerythrin}

Fig. 6. The presence / absence of phycobilisome synthesis genes in the green and red Pseudanabaena isolates, as well as Pseudanabaena biceps PCC 7429. For each gene, a colored square indicates the presence of the gene in the genome of Pseudanabaena UWO310 (green), Pseudanabaena UWO311 (red), and P. biceps PCC 7429 (grey). White indicates that a homolog of this gene was not found in the genome. 

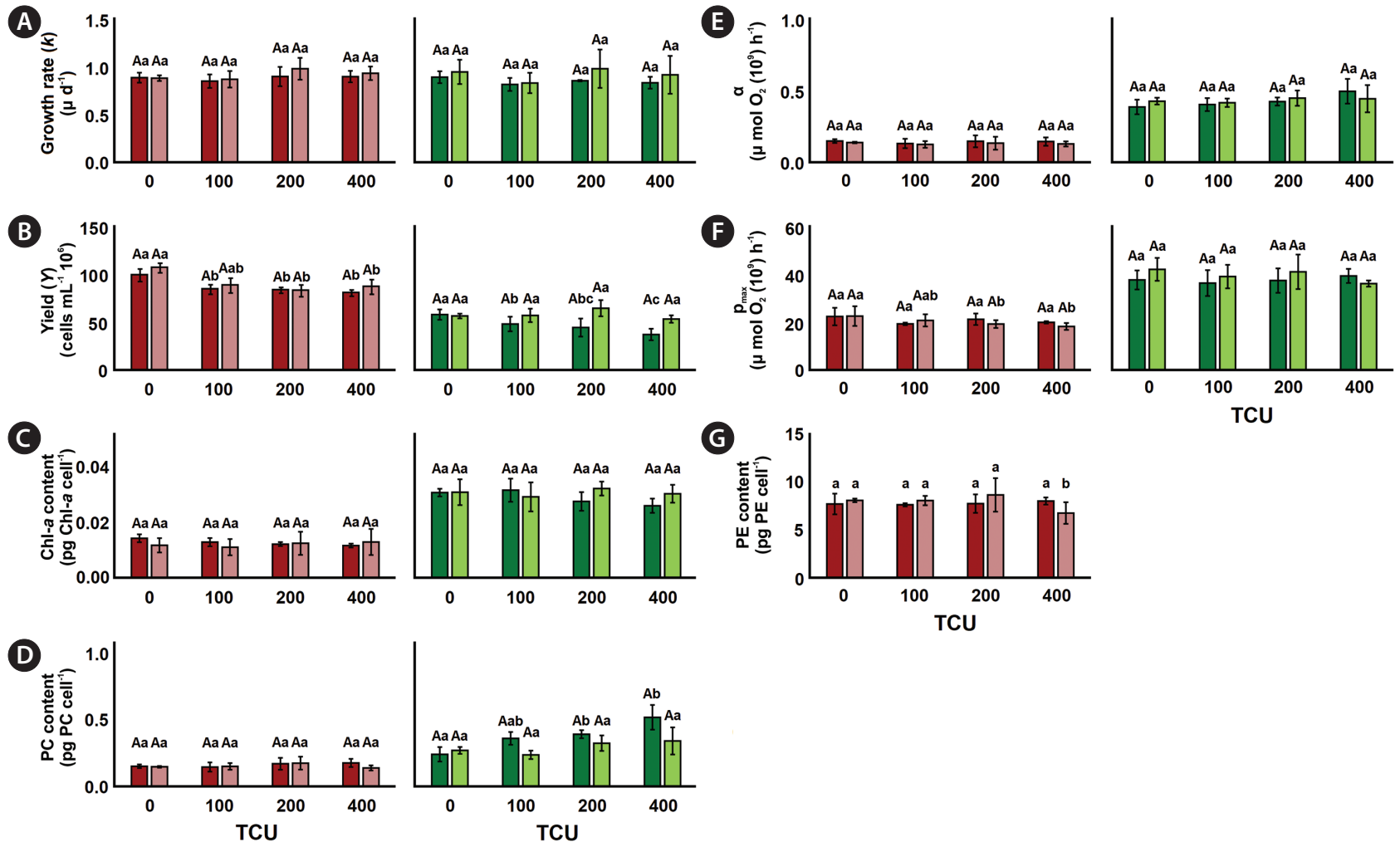

Fig. 7. Growth rate $(k)(A)$, yield $(Y)(B)$, chlorophyll-a content (pg Chl-a cell $\left.{ }^{-1}\right)(C)$, phycocyanin $(P C)$ content (pg PC cell $\left.{ }^{-1}\right)(D)$, light-limited rates of photosynthesis $(a)(E)$, enzyme-limited rates of photosynthesis $\left(P_{\max }\right)(F)$, and phycoerythrin $(P E)$ content $\left(p g P E\right.$ cell $\left.{ }^{-1}\right)(G)$ under different concentrations of dissolved organic matter (DOM; expressed in true color units [TCU]) of the red and green phenotypes of Pseudanabaena (values expressed as mean \pm standard deviation, $n=3$ ). Symbol colors represent results for the red phenotype [physical (DOM external to media, $\square$ ) and physical / chemical (DOM added to media, $\square$ )] and the green phenotype [physical ( $\square$ )] and physical / chemical ( $\square$ )]. Same lowercase letters indicate no significant effect of DOM on the phenotype. Same uppercase letters indicate no significant effect of experimental design on the phenotype.

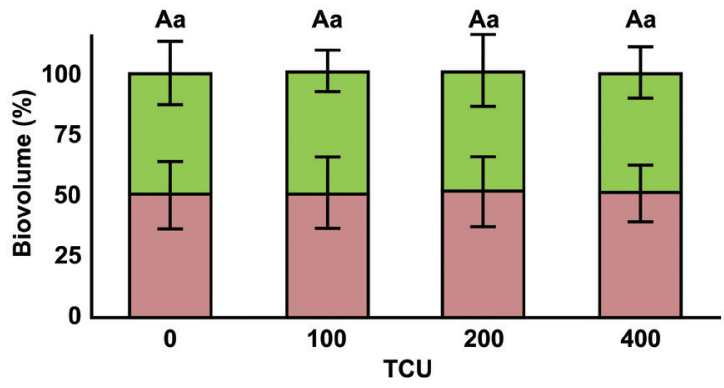

Fig. 8. Relative volume of cells for the red $(\square)$ and green $(\square)$ phenotypes of Pseudanabaena (mean \pm standard deviation, $\mathrm{n}=3$ ). Same lowercase letters indicate no significant effect of dissolved organic matter (DOM) on the red phenotype. Same uppercase letters indicate no significant effect of DOM on the green phenotype. TCU, true color units.

\section{DOM affects pigment synthesis}

When each isolate was grown individually under the distinct level of light-attenuating DOM additions, growth rate was not significantly different $(p>0.05)$ for either phenotype across all DOM treatments $(0,100,200$, or 400 TCU), and growth rate was not significantly different ( $\mathrm{p}$ $>0.05$ ) between DOM additions to the media and placed externally to the culture flask at the same DOM concentrations (Fig. 7A). Cell yield was significantly higher ( $\mathrm{p} \leq$ 0.05 ) for the red phenotype when no DOM was supplied (0 TCU) compared to when DOM was present $(100,200$, or $400 \mathrm{TCU})$. In contrast, cell yield was not significantly different $(p>0.05)$ for the green phenotype among DOM treatments $(0,100,200$, or $400 \mathrm{TCU})$ in either experimental design. Cell yield was also not significantly different ( $p>0.05$ ) for either phenotype between internal and external DOM additions at similar concentrations (Fig. 7B).

Chl- $a$ content remained similar ( $\mathrm{p}>0.05$ ) for each organism across all DOM treatments and across both experimental designs (Fig. 7C). The PC content remained similar ( $p>0.05$ ) for the red phenotype across DOM treatments in both experimental designs (Fig. 7D). In contrast, significant effects $(p \leq 0.05)$ were observed for the green phenotype with elevated PC content with increas- 
ing DOM in the external DOM experiment. In the DOM addition experiment, while PC content in the green phenotype increased with increasing DOM, the differences were not statistically significant. For the red phenotype, PE content did not change significantly $(p>0.05)$ across all DOM treatments in the external experiment, but was significantly different $(\mathrm{p} \leq 0.05)$ in the DOM addition experiment where PE content was lower for the highest DOM treatment (Fig. 7G). However, no significant differences ( $p>0.05$ ) were reported among phycobilin content for both phenotypes between DOM additions and external DOM at similar concentrations.

Light-limited rates were also comparable $(p>0.05)$ for each organism across all DOM treatments in the external experiment (Fig. 7E). In contrast, enzyme-limited rates were significantly different $(\mathrm{p} \leq 0.05)$ in the red phenotype DOM addition experiment but were not significantly different $(p>0.05)$ in the green phenotype (Fig. $7 F)$. Again, no significant effects $(p>0.05)$ were revealed among $\mathrm{P}_{\max }$ for both phenotypes between DOM addition and external DOM at similar concentrations.

\section{No competition between phenotypes}

When the two isolates were grown together under distinct levels of light-attenuating DOM additions, there was no selection based on the relative proportion of the cells. Relative abundances of the red and green phenotype remained constant $(p>0.05)$ over time, with approximately $50 \%$ red and $50 \%$ green phenotype reported across all DOM treatments (Fig. 8).

\section{DISCUSSION}

While the cause of the environmental transition of Dickson Lake remains under consideration, the outcome of this perturbation was evident-a dense Dolichospermum bloom with two distinct Pseudanabaena phenotypes. The phylogenetic and genomic analysis confirms that these are Pseudanabaena isolates and reveals that the red and green phenotypes are sufficiently genetically distinct to recognize them as different species. Many cyanobacteria are morphologically similar to strains in the Pseudanabaena clade that includes the red and green phenotypes. Still, they are distantly related based on phylogenetic analyses, resulting in problematic taxonomy, polyphyletic genera, or unrecognized cryptic diversity (Dvořák et al. 2015, Konstantinou et al. 2021). Here, the red phenotype (UWO311) clusters strongly with $L$. rede- kei CCAP 1443/1, but this Limnotrix strain is distantly related to other $L$. redekei strains, and should be transferred to the genus Pseudanabaena. Similarly, A. gigaxiana, the closest relative of the green phenotype (UWO310) and Oscillatoria limnetica MR1, requires taxonomic revision. Notwithstanding these taxonomic issues, the green and red phenotypes group within the Pseudanabaena and will be considered as Pseudanabaena strains.

Members of the Pseudanabaena genus have been reported worldwide, identified across the freshwater-marine continuum, demonstrating the adaptability of the genus (Acinas et al. 2009, Kling et al. 2012). Initially, the presence of multiple phenotypes led us to explore if these phenotypes were the result of chromatic adaptation, perhaps a trait that might explain their co-occurrence. However, we found no evidence of chromatic adaptation. In fact, the green phenotype did not produce detectable amounts of PE; the genes to synthesize PE were absent in this phenotype. Although these Pseudanabaena isolates did not chromatically adapt under the tested conditions, their genomes possess two genes responsible for regulating chromatic adaptation, CcaR and CcaS (Kehoe 2010). These genes assist in the activation of pigment synthesis genes under different wavelengths of light. For example, under green light, CcaS phosphorylates CcaR and then the phosphorylated CcaR assists in the activation of PE synthesis genes allowing the cyanobacterium to become red and absorb green light (Stomp et al. 2007, Hirose et al. 2008). However, these genes likely have a light-sensing function that enables the regulation of complementary chromatic adaptation and are present in non-chromatically adapting cyanobacteria as well (Kehoe and Gutu 2006).

Increased browning has been proposed as a catalyst behind cyanobacteria bloom formation in northern freshwaters (Creed et al. 2018), and it is important to distinguish which cyanobacteria genera may flourish. As each phenotype presents a unique pigment profile, each likely evolved to exploit different environmental niches. By occupying different niches (i.e., depths), browning may result in different phenotypical responses, favouring one phenotype at the other's expense. We predicted that with increased browning, the cellular performance (i.e., growth and photosynthetic response) of the green phenotype of Pseudanabaena would be greater than the red phenotype based on light energy distribution. However, the growth and photosynthetic parameters of the two phenotypes remained insensitive to the addition of the putative driving variable of bloom-formation in northern lakes-increased DOM. Even under a competitive 
design, no competitively dominant phenotype appeared under defined DOM regimes.

While photosynthetic pigment diversity among phytoplankton offers subtle opportunities for niche-differentiation, this study's results illustrate the coexistence of two closely related but distinct species with different pigment compositions under increased DOM concentrations. This unexpected outcome suggests that other factors, aside from pigment diversity, assist in coexistence and illustrates the importance of understanding species-specific responses in predicting how lake browning will alter cyanobacteria diversity. Due to the continued browning of freshwater lakes, it is crucial to understand whether additions of DOM will promote or decrease cyanobacterium growth and identify which specific cyanobacteria will show dominance under the "new normal" projected for northern freshwaters.

\section{ACKNOWLEDGEMENTS}

This work was funded by an NSERC Discovery Grants 06579-2014 and 4458-2016 awarded to IFC and CGT, respectively, and an NSERC CREATE ABATE awarded to IFC and CGT (448172-2014) and Western Strategic Funds awarded to VT.

\section{CONFLICTS OF INTEREST}

The authors declare that they have no potential conflicts of interest.

\section{REFERENCES}

Acinas, S. G., Haverkamp, T. H. A., Huisman, J. \& Stal, L. J. 2009. Phenotypic and genetic diversification of Pseudanabaena spp. (cyanobacteria). ISME J. 3:31-46.

Andersen, R. A. 2005. Algal culturing techniques. Elsevier, New York, 578 pp.

Bankevich, A., Nurk, S., Antipov, D., Gurevich, A. A., Dvorkin, M., Kulikov, A. S., Lesin, V. M., Nikolenko, S. I., Pham, S., Prjibelski, A. D., Pyshkin, A. V., Sirotkin, A. V., Vyahhi, N., Tesler, G., Alekseyev, M. A. \& Pevzner, P. A. 2012. SPAdes: a new genome assembly algorithm and its applications to single-cell sequencing. J. Comput. Biol. 19:455-477.

Capella-Gutiérrez, S., Silla-Martínez, J. M. \& Gabaldón, T. 2009. trimAl: a tool for automated alignment trimming in large-scale phylogenetic analyses. Bioinformatics
25:1972-1973.

Creed, I. F., Bergström, A. -K., Trick, C. G., Grimm, N. B., Hessen, D. O., Karlsson, J., Kidd, K. A., Kritzberg, E., McKnight, D. M., Freeman, E. C., Senar, O. E., Andersson, A., Ask, J., Berggren, M., Cherif, M., Giesler, R., Hotchkiss, E. R., Kortelainen, P., Palta, M. M., Vrede, T. \&Weyhenmeyer, G. A. 2018. Global change-driven effects on dissolved organic matter composition: implications for food webs of northern lakes. Glob. Change Biol. 24:3692-3714.

Dvořák, P., Jahodářová, E., Hašler, P., Gusev, E. \& Poulíčková, A. 2015. A new tropical cyanobacterium Pinocchia polymorpha gen. et sp. nov. derived from the genus Pseudanabaena. Fottea 15:113-120.

Ekvall, M. K., de la Calle Martin, J., Faassen, E. J., Gustafsson, S., Lürling, M. \& Hansson, L. -A. 2013. Synergistic and species-specific effects of climate change and water colour on cyanobacterial toxicity and bloom formation. Freshw. Biol. 58:2414-2422.

Erratt, K. J., Creed, I. F. \& Trick, C. G. 2018. Comparative effects of ammonium, nitrate and urea on growth and photosynthetic efficiency of three bloom-forming cyanobacteria. Freshw. Biol. 63:626-638.

Favot, E. J., Rühland, K. M., DeSellas, A. M., Ingram, R., Paterson, A. M. \& Smol, J. P. 2019. Climate variability promotes unprecedented cyanobacterial blooms in a remote oligotrophic Ontario lake: evidence from paleolimnology. J. Paleolimnol. 62:31-52.

Friends of Algonquin Park. 2015. Algae bloom update-Dickson Lake and Lake Lavieille. Available from: https:// www.algonquinpark.on.ca/news/2015/2015-02-17_ dickson_lake_algae_bloom_update.php. Accessed Mar 4, 2021.

Grébert, T., Doré, H., Partensky, F., Farrant, G. K., Boss, E. S., Picheral, M., Guidi, L., Pesant, S., Scanlan, D. J., Wincker, P., Acinas, S. G., Kehoe, D. M. \& Garczarek, L. 2018. Light color acclimation is a key process in the global ocean distribution of Synechococcus cyanobacteria. Proc. Natl. Acad. Sci. U. S. A. 115:E2010-E2019.

Green, N. W., McInnis, D., Hertkorn, N., Maurice, P. A. \& Perdue, E. M. 2015. Suwannee River natural organic matter: isolation of the $2 \mathrm{R} 101 \mathrm{~N}$ reference sample by reverse osmosis. Environ. Eng. Sci. 32:38-44.

Guillard, R. R. L. 1973. Division rates. In Stein, J. R. (Ed.) Handbook of Phycological Methods: Culture Methods and Growth Measurements. Cambridge University Press, Cambridge, pp. 289-312.

Guillard, R. R. L. \& Sieracki, M. S. 2005. Counting cells in cultures with the light microscope. In Andersen, R. A. (Ed.) Algal Culturing Techniques. Elsevier, New York, pp. 239-252. 
Gurevich, A., Saveliev, V., Vyahhi, N. \& Tesler, G. 2013. QUAST: quality assessment tool for genome assemblies. Bioinformatics 29:1072-1075.

Haverkamp, T. H. A., Schouten, D., Doeleman, M., Wollenzien, U., Huisman, J. \& Stal, L. J. 2009. Colorful microdiversity of Synechococcus strains (picocyanobacteria) isolated from the Baltic Sea. ISME J. 3:397-408.

Hirose, Y., Shimada, T., Narikawa, R., Katayama, M. \& Ikeuchi, M. 2008. Cyanobacteriochrome CcaS is the green light receptor that induces the expression of phycobilisome linker protein. Proc. Natl. Acad. Sci. U. S. A. 105:9528-9533.

Huisman, J., Jonker, R. R., Zonneveld, C. \& Weissing, F. J. 1999. Competition for light between phytoplankton species: experimental tests of mechanistic theory. Ecology 80:211-222.

Hutchinson, G. E. 1961. The paradox of the plankton. Am. Nat. 95:137-145.

Jeffrey, S. W. \& Humphrey, G. F. 1975. New spectrophotometric equations for determining chlorophylls $a, b, c 1$ and $c 2$ in higher-plants, algae and natural phytoplankton. Biochem. Physiol. Pfl. 167:191-194.

Kanehisa, M., Sato, Y. \& Morishima, K. 2016. BlastKOALA and GhostKOALA: KEGG tools for functional characterization of genome and metagenome sequences. J. Mol. Biol. 428:726-731.

Karlsson, J., Byström, P., Ask, J., Ask, P., Persson, L. \& Jansson, M. 2009. Light limitation of nutrient-poor lake ecosystems. Nature 460:506-509.

Katoh, K. \& Standley, D. M. 2013. MAFFT multiple sequence alignment software version 7: improvements in performance and usability. Mol. Biol. Evol. 30:772-780.

Kehoe, D. M. 2010. Chromatic adaptation and the evolution of light color sensing in cyanobacteria. Proc. Natl. Acad. Sci. U. S. A. 107:9029-9030.

Kehoe, D. M. \& Gutu, A. 2006. Responding to color: the regulation of complementary chromatic adaptation. Annu. Rev. Plant Biol. 57:127-150.

Kling, H. J., Dail Laughinghouse, H. D., Šmarda, J., Komárek, J., Acreman, J., Bruun, K., Watson, S. B. \& Chen, F. 2012. A new red colonial Pseudanabaena (Cyanoprokaryota, Oscillatoriales) from North American large lakes. Fottea 12:327-339.

Konstantinou, D., Voultsiadou, E., Panteris, E. \& Gkelis, S. 2021. Revealing new sponge-associated cyanobacterial diversity: novel genera and species. Mol. Phylogenet. Evol. 155:106991.

Kritzberg, E. S., Hasselquist, E. M., Škerlep, M., Löfgren, S., Olsson, O., Stadmark, J., Valinia, S., Hansson, A. \& Laudon, H. 2019. Browning of freshwaters: consequenc- es to ecosystem services, underlying drivers, and potential mitigation measures. Ambio 49:375-390.

Lawrenz, E., Fedewa, E. J. \& Richardson, T. L. 2011. Extraction protocols for the quantification of phycobilins in aqueous phytoplankton extracts. J. Appl. Phycol. 23:865-871.

Martin, M. 2011. Cutadapt removes adapter sequences from high-throughput sequencing reads. EMBnet J. 17:10-12.

Maxwell, D. P., Falk, S., Trick, C. G. \& Huner, N. P. A. 1994. Growth at low temperature mimics high-light acclimation in Chlorella vulgaris. Plant Physiol. 105:535-543.

Neary, B. P., Dillon, P. J., Munro, J. R. \& Clark, B. J. 1990. The acidification of Ontario lakes: an assessment of their sensitivity and current status with respect to biological damage. Ontario Ministry of the Environment. Available from: https://www.biodiversitylibrary.org/item/78250. Accessed Mar 4, 2021.

Oberhaus, L., Briand, J. F., Leboulanger, C., Jacquet, S. \& Humbert, J. F. 2007. Comparative effects of the quality and quantity of light and temperature on the growth of Planktothrix agardhii and P. rubescens. J. Phycol. 43:1191-1199.

Pagano, T., Bida, M. \& Kenny, J. E. 2014. Trends in levels of allochthonous dissolved organic carbon in natural water: a review of potential mechanisms under a changing climate. Water 6:2862-2897.

Rippka, R., Deruelles, J., Waterbury, J. B., Herdman, M. \& Stanier, R. Y. 1979. Generic assignments, strain histories and properties of pure cultures of cyanobacteria. J. Gen. Microbiol. 111:1-61.

Ronquist, F., Teslenko, M., van der Mark, P., Ayres, D. L., Darling, A., Höhna, S., Larget, B., Liu, L., Suchard, M. A. \& Huelsenbeck, J. P. 2012. MrBayes 3.2: efficient Bayesian phylogenetic inference and model choice across a large model space. Syst. Biol. 61:539-542.

Seemann, T. 2014. Prokka: rapid prokaryotic genome annotation. Bioinformatics 30:2068-2069.

Senar, O. E., Creed, I. F. \& Trick, C. G. 2021. Lake browning may fuel phytoplankton biomass and trigger shifts in phytoplankton communities in temperate lakes. Aquat. Sci. 83:1-15.

Simão, F. A., Waterhouse, R. M., Ioannidis, P., Kriventseva, E. V. \& Zdobnov, E. M. 2015. BUSCO: assessing genome assembly and annotation completeness with single-copy orthologs. Bioinformatics 31:3210-3212.

Solomon, C. T., Jones, S. E., Weidel, B. C., Buffam, I., Fork, M. L., Karlsson, J., Larsen, S., Lennon, J. T., Read, J. S., Sadro, S. \& Saros, J. E. 2015. Ecosystem consequences of changing inputs of terrestrial dissolved organic matter to lakes: current knowledge and future challenges. Ecosystems 18:376-389. 
Stamatakis, A. 2014. RAxML version 8: a tool for phylogenetic analysis and post-analysis of large phylogenies. Bioinformatics 30:1312-1313.

Stomp, M., Huisman, J., De Jongh, F., Veraart, A. J., Gerla, D., Rijkeboer, M., Ibelings, B. W., Wollenzien, U. I. \& Stal, L. J. 2004. Adaptive divergence in pigment composition promotes phytoplankton biodiversity. Nature 432:104-107.

Stomp, M., Huisman, J., Vörös, L., Pick, F. R., Laamanen, M., Haverkamp, T. \& Stal, L. J. 2007. Colourful coexistence of red and green picocyanobacteria in lakes and seas. Ecol. Lett. 10:290-298.

Urrutia-Cordero, P., Ekvall, M. K. \& Hansson, L. A. 2016. Local food web management increases resilience and buffers against global change effects on freshwaters. Sci. Rep. 6:29542.

Wells, M. L., Trainer, V. L., Smayda, T. J., Karlson, B. S. O., Trick, C. G., Kudela, R. M., Ishikawa, A., Bernard, S., Wulff, A., Anderson, D. M. \& Cochlan, W. P. 2015. Harmful algal blooms and climate change: Learning from the past and present to forecast the future. Harmful Algae 49:68-93.

Wood, A. M., Everroad, R. C. \&Wingard, L. M. 2005. Measuring growth rates in microalgal cultures. In Andersen, R. A. (Ed.) Algal Culturing Techniques. Elsevier Academic Press, Burlington, MA, pp. 269-285. 